\title{
O ESPAÇO URBANO E O CAPITAL: UMA ANÁLISE A PARTIR DO PRECEITO CONSTITUCIONAL DA FUNÇÃO SOCIAL DA CIDADE
}

\author{
Paulo Henrique Tavares da Silva* \\ Éverton Gonçalves Moraes ${ }^{* *}$
}

\section{RESUMO}

O trabalho tem por objetivo suscitar o debate teórico ao panorama da influência do capital na formação do espaço urbano, discutindo como o modo capitalista domina a disposição do solo urbano, a fim de atender as suas próprias demandas. Assim, considerando o espaço urbano como fruto do trabalho humano, propõe-se um estudo sobre a sua morfologia, analisando o domínio dos meios de produção e da força do trabalho pelo capital, contrapondo-o ao princípio da função social da cidade. A pesquisa adotará caráter descritivo, com abordagem dedutiva, e análise sistematizada das informações através de pesquisa bibliográfica.

PALAVRAS-CHAVE: Função Social; Direito à Cidade; Capital; Trabalho; Espaço Urbano.

\section{THE URBAN SPACE AND CAPITAL: AN ANALYSIS A PARTY OF THE CONSTITUTIONAL PRECIPITATION OF THE CITY SOCIAL FUNCTION}

\begin{abstract}
The objective of this work is to raise the theoretical debate about the influence of capital in the formation of urban space, discussing how the capitalist mode dominates the urban land layout in order to meet its own demands. Thus, considering the urban space as a result of human work, a study is proposed on its morphology, analyzing the domain of the means of production and the labor force by capital, opposing it to the principle of the social function of the city. The research will be descriptive, with a deductive approach, and systematized analysis of information through bibliographic research.
\end{abstract}

KEYWORDS: Social role; Right to the City; Capital; Work; Urban Space.

\section{INTRODUÇÃO}

Considerar o espaço apenas como um produto do trabalho humano, proveniente das relações sociais, onde o homem modifica a natureza através do seu trabalho seria algo demasiadamente simples, todavia, para se entender a lógica produtiva do espaço é necessário antes de tudo analisar a lógica da dominação do trabalho humano pelo capital. Partindo-se desta premissa, pode-se afirmar que a produção do espaço se dá pelas relações sociais, numa

\footnotetext{
${ }^{*}$ Doutor e Mestre em Direito pela UFPB, professor da UFPB/CCJ. Professor do PPGD/UNIPÊ. Líder do GP Estado, Sociedade Civil e Desenvolvimento Econômico Sustentável. E-mail: prof.paulohenriquetavares@gmail.com.

* Mestrando em Direito e Desenvolvimento Sustentável - PPGD/UNIPÊ. Professor de Direito da Faculdade de Filosofia, Ciências e Letras de Cajazeiras - FAFIC. Integrante do GP Estado, Sociedade Civil e Desenvolvimento Econômico Sustentável. E-mail: evertonmoraes@ fescfafic.edu.br.

Revista de Direito Urbanístico, Cidade e Alteridade | e-ISSN: 2525-989X | Salvador | v. 4 | n. 1 | p. 95 - 112 | 
perspectiva que vai além do puro dualismo homem-natureza, sendo necessário um exame da própria formação social, num contexto de uma complexa estrutura organizada em instâncias econômicas, político-jurídicas e ideológicas, articuladas e determinadas pelas relações e fatores de produção dominados pelo capitalismo.

Trazer esta análise para o fenômeno da grande expansão dos centros urbanos, tornase de suma importância para o estudo das questões socioambientais da cidade, em especial para a discussão de um planejamento e uma estruturação urbana que seja capaz de atender estas demandas. Dessa maneira, não é mais plausível imaginar que a organização e o planejamento urbano de uma cidade possam ser feitos de qualquer modo ou por mera discricionariedade da administração pública em prol de um melhor escoamento e absorção do excedente do capital.

A presente pesquisa se propõe a abordar a influência do capital na morfologia do espaço urbano, a partir do domínio dos meios de produção, da força do trabalho e da influência capitalista na própria estrutura estatal. A partir daí, far-se-á um contraponto com o preceito constitucional da função social da cidade que prescreve o direito de se ter uma estruturação urbana pensada de maneira a desenvolver o bem-estar de seus habitantes, numa trajetória de expansão sustentável e justa. Assim, pretende-se iniciar uma discussão teórica entorno da seguinte indagação: qual a influência do capital na formação do espaço urbano em vistas ao cumprimento da função social da cidade?

Para tanto, a pesquisa adotará um caráter descritivo, no intuito de demonstrar as características da influência do capital no fenômeno da criação do espaço urbano, bem como estabelecer a relações entre variáveis e fatos, com uma abordagem dedutiva, que envolve a análise das informações coletadas de maneira sistematizada através de pesquisa bibliográfica, tendo como base da fundamentação teórica as obras de David Harvey, Alain Lipietz, Karl Marx, José Afonso da Silva e outros. E procedimentalmente, será utilizado o método histórico, vez que será estudado a evolução histórica do espaço urbano numa perspectiva do desenvolvimento deste a partir da influência do capital. Assim, far-se-á uma análise ao caso da modernização urbanística pela qual passou a cidade de Paris, em meados do século XIX. Logo, tomar-se-á Paris como objeto de análise para demonstrar a dinâmica entre o capital, o Estado, e a formação do espaço urbano, utilizando-se para isso a técnica de pesquisa bibliográfica. 


\section{UMA BREVE ANÁLISE DA PRODUÇÃO DO ESPAÇO SOCIAL: MEIOS DE PRODUÇÃO, RELAÇÕES DE TRABALHO E O CAPITAL}

A sociedade produz espaços díspares de acordo com as diferentes técnicas utilizadas, logo, pode-se dizer que as transformações do espaço se dão de forma mais rápida ou mais lenta o que dependerá do tipo de procedimento utilizado. Assim, as técnicas atuais, representadas pelos meios sociais e instrumentais modernos produzem os espaços de maneira muito mais rápida do que aquelas empregadas nas sociedades mais antigas.

A técnica, segundo Milton Santos (2002), desempenha um papel de extrema importância na diferenciação dos espaços e para se perceber isto basta que se analise a diferenciação entre os países do Norte, tido como desenvolvidos, e os países do Sul que ainda estão em desenvolvimento. Enquanto os primeiros são detentores de avançadas tecnologias, os do hemisfério Sul são dependentes destes e importam suas tecnologias. Logo, este cenário dual entre aqueles que detém mais tecnologia e aqueles que são privados dela, irá influenciar de maneira considerável na diferenciação da criação dos espaços.

O espaço pode ser considerado, então, como produto do trabalho humano, uma vez que a produção do espaço se dá a partir das relações sociais, onde o homem modifica a natureza através do seu trabalho. A ideia de que a produção do espaço se dá pelas relações sociais, transcende as barreiras de uma mera dualidade entre homem e natureza, na verdade, a compreensão da formação espacial é, antes de tudo, compreender a própria formação social, num contexto de uma complexa estrutura organizada em instâncias econômicas, políticojurídicas e ideológicas, articuladas e determinadas pelas relações de produção (LIPIETZ, 1988).

Diz-se que a produção do espaço se trata de uma cadeia ordenada de operações com resultados coexistentes temporal e espacialmente, em vista de um determinado objetivo, o produzir. Ora, a prática social cria obras e produz coisas, sendo que não é possível produzir ou criar, o que quer que seja, sem a necessária participação do trabalho humano, vez que, é através dele que o homem orienta suas ações e direciona os elementos materiais e espaciais para alcançar objetivos pré-determinados.

Assim, o espaço social pode ser considerado resultado da produção humana, não sendo exatamente uma coisa ou um produto específico, mas um conjunto de todas as coisas produzidas, uma junção de todas as relações em sua coexistência. Não se trata de um simples 
objeto, mas de um conjunto coordenado de operações (ações), não só de produção, mas também de consumo. (LEFEBVRE, 2006).

De fato, os meios de produção alteram ou criam novos espaços, mas o fazem através do trabalho humano, já que é ele que torna possível a utilização da própria cadeia produtiva. Noutro ponto, cabe destacar também a importância dos meios de consumo, pois não faz sentido produzir sem se consumir. Desse modo, a relação entre produção, trabalho e consumo, torna-se o eixo central da criação do espaço, pois não haveria produção do espaço sem a presença do trabalho humano, ao ponto que só se produz aquilo que alguém está disposto a consumir. (SANTOS, 1996).

Destarte, pode-se afirmar que é justamente através do trabalho que o homem produz as condições do espaço, organizando-o numa estrutura política, econômica, social e até mesmo intelectual, de acordo com as concepções inerentes a cada grupo dominante de cada lugar e de cada tempo.

Para reforçar essa ideia, toma-se por base o exemplo trazido por Henri Lefebvre (2006) que se refere à Toscana na Itália do século XIII, onde a oligarquia urbana instalou um novo sistema de produção no campo, o "colonato precário", no qual o colono (pessoa que produzia na terra em nome de seu proprietário) ficava com parte da produção para si e o restante era destinado ao dono da terra. Estes colonos não se enquadravam como escravos, nem tampouco como servos, pois recebiam parte da produção, algo que buscava encorajá-los a produzir cada vez mais.

Esta relação citada por Lefebvre traduz a forma de como a produção e o trabalho podem alterar os espaços sociais, como afirma o autor o "colonato precário" inaugura uma nova estrutura na cadeia de produção, onde os proprietários entenderam que seria necessário desenvolver uma nova técnica que tornasse o trabalho mais viável e consequentemente mais produtivo.

\subsection{Da produção do espaço pelo capital}


Antes de teorizar sobre o papel do capital na relação entre os meios de produção do espaço, se faz necessário conceituar os institutos do capital e do capitalismo. Assim, o capital pode ser conceituado por dois aspectos, de um lado se apresenta como um valor em dinheiro investido num empreendimento ou transação com a pretensão de se obter lucro. De outro modo, destaca-se também por ser o detentor dos meios de produção e que mesmo sem dinheiro agrega valor aos seus produtos em decorrência da exploração dos meios produtivos. O capitalismo, por sua vez, tem início com o apoio das cidades-estados italianas à Europa ocidental nas Cruzadas (séculos XIII e XIV), somado ao grande acúmulo de riquezas provenientes das grandes expedições marítimas que iniciaram no século XVI e que ensejou na descoberta de ouro e prata na América, nos saques das Índias Orientais, além do comércio de escravos provenientes da África (HUBERMAN, 1981).

A partir desta breve conceituação, aponta-se que a produção capitalista seria então o somatório da força de trabalho aos meios de produção, sendo que essa nova cadeia produtiva, norteada pelo capital, passa a alterar, de certo modo, a produção do espaço social.

Até a insurreição dos novos modos de produção capitalistas, consequência do próprio renascimento mercantil europeu que se iniciou com o retorno dos cruzados, a realidade espacial era aquela provinda do feudalismo, ou seja, tínhamos uma sociedade basicamente rural, sendo que a partir do ressurgimento e fortalecimento do comércio e mais tarde pelo avanço da indústria, a população começou a ficar cada vez mais dependente da cidade.

Esta movimentação espacial pode ser percebida historicamente, por exemplo, na Itália, em cidades como Veneza, Gênova e Pisa onde surge uma nova forma de organização espacial, que tem por base a própria relação do indivíduo no espaço e não mais a simples dualidade cidade e campo, considerados isoladamente.

Assim, a superação da dualidade concreta entre campo e cidade se apresenta como uma das primeiras condições da própria comunidade e está intimamente ligada a nova concepção de propriedade trazida pelo capital.

A separação entre cidade e campo também pode ser apreendida como a separação entre capital e propriedade da terra, como o início de uma existência e de um desenvolvimento do capital independentes da propriedade da terra, o início de uma propriedade que tem como base apenas o trabalho e a troca (MARX, 2007, p.52).

Nessa linha, Alain Lipietz (1988) chama a atenção para o papel da produção capitalista do espaço na França, onde os modos de produção do capital se apropriam dos 
modos pré-capitalistas. Assim, o sistema de produção que era voltado basicamente à agricultura, ao artesanato e ao comércio, perdeu o seu protagonismo para novos fatores de produção, especialmente o industrial. Restando então, aos antigos meios de produção apenas duas funções: ser uma reserva de mão de obra; e ao mesmo tempo, um mercado para consumo dos produtos provenientes dos novos modos de produção.

É importante salientar que esses novos fatores de produção passaram a exigir novas técnicas que, por sua vez, iriam gerar novos produtos que não podiam ser produzidos sem a intervenção da mão-de-obra, fazendo com que a força do trabalho passasse a ser fator preponderante para os novos métodos capitalistas. Assim, dominar a força de trabalho era garantia de maior produção e maior lucratividade.

No mesmo sentido, de nada adiantaria produzir em grande escala se estes produtos não fossem consumidos, assim deveria haver também uma metodologia que tornasse possível lucrar duas vezes através do trabalho, uma delas era pagar menos em salários do que o custo do produto, e de outro modo, pagar um salário que tornasse possível ao trabalhador realizar o consumo do que fora produzido.

Os novos meios de produção, baseados e dominados pelo capital, irão influenciar a partir de então, de maneira decisiva na produção do espaço social e especialmente no que tange a formação das cidades e na forma como estas se relacionam com os seus cidadãos.

Toda esta nova conjuntura social estará estruturada a partir dos interesses do capital que passa a ter o domínio dos meios de produção e a determinar, consequentemente, as formas das relações de trabalho, o que acarretou na formação de novos espaços.

Assim, destaca-se que é na cidade, ponto de concentração da população e objeto deste estudo, que os instrumentos de fruição do capital, em especial a força do trabalho e a propriedade privada, mostraram-se de forma mais dinâmica e eficaz.

A cidade é, de pronto, o fato da concentração da população, dos instrumentos de produção, do capital, das fruições, das necessidades, enquanto o campo evidencia exatamente o fato contrário, a saber, o isolamento e a solidão. A oposição entre cidade e campo só pode existir no interior da propriedade privada. É a expressão mais crassa da subsunção do indivíduo à divisão do trabalho, a uma atividade determinada, a ele imposta - uma subsunção que transforma uns em limitados animais urbanos, outros em limitados animais rurais e que diariamente reproduz a oposição entre os interesses de ambos. O trabalho é, aqui, novamente o fundamental, o poder sobre os indivíduos, e enquanto existir esse poder tem de existir a propriedade privada. A superação da oposição entre cidade e campo é uma das primeiras condições da comunidade, uma condição que, por seu turno, depende de 
uma massa de pressupostos materiais e que não pode ser satisfeita pela mera vontade, como qualquer um pode constatar à primeira vista (MARX, 2007, p.52).

Eis que essa nova realidade de expansão e criação do espaço urbano se alargou pela Europa principalmente a partir do século XIX, tendo como uma de suas principais características as relações de trabalho e a exploração destas pelo capital, como dito anteriormente.

E qual a relação destas novas técnicas capitalistas com a criação do espaço? Para se responder a esta indagação é necessário lembrar que o capital predomina por conta de sua dominação aos meios de produção e uma das maneiras desta dominação é a retirada do trabalhador do seu lugar (do campo), levando-o para outras localidades, quebrando suas origens, sua cultura, seus costumes, sua identidade.

Na verdade, o que ocorre é que aquele que domina os meios de produção também domina o trabalho, assim, o trabalhador não busca mais uma satisfação pessoal na relação de trabalho, pois não é mais o dono do seu trabalho. Assim, o resultado será a exploração da mão de obra e a satisfação do capitalista que irá obter cada vez mais lucros, do mesmo modo que a produção do espaço urbano será voltada para facilitar esta exploração e para aumentar ainda mais as possiblidades de lucratividade.

Basta imaginar diante do contexto histórico aqui analisado, que a sociedade Medieval até o surgimento e fortalecimento do capitalismo era em sua grande maioria formada por populações rurais, que tiravam sua subsistência da terra. O sistema capitalista modifica esta conjuntura social, alterando e dominando os meios de produção, pondo fim a antigas práticas de subsistência familiar, e exigindo a produção de excedentes para fins lucrativos passa a delimitar também a própria produção do espaço.

Para entendermos melhor este cenário de transição que se atrela ainda a dualidade de espaço, entre campo e cidade, pode-se citar um pequeno trecho da obra "A origem do capital: a acumulação primitiva" na qual Marx descreve a realidade da expropriação dos camponeses ingleses.

[...] Os burgueses capitalistas favoreciam a operação com fim de fazer da terra um artigo de comércio, de aumentar as suas reservas de proletariados do campo, de ampliar a agricultura em grande escala etc.

De resto, a nova aristocracia latifundiária era aliada natural da nova bancocracia, de alta finança, recentemente nascida e das grandes manufaturas, então fatores do sistema protecionista. A burguesia inglesa agia de conformidade com os seus 
próprios interesses, do mesmo modo que a burguesia sueca, a fim de ajudar os reis a retomar por medidas violentas as terras da coroa, usurpadas pela aristocracia (MARX, 1981, p. 33-34).

Vale salientar que no sistema mercantil pré-capitalista, o trabalhador era o proprietário dos meios de produção e do produto, sendo que a finalidade deste não é outra senão a sua subsistência e da sua família. Já no sistema capitalista, a relação produtiva passa a ter outras interferências, por exemplo, o alto custo para a manutenção da propriedade proveniente da cobrança de impostos, hipotecas, dentre outros, o que obrigava ao produtor a colocar o seu produto excedente no mercado, de modo que ele passava a depender do capital e suas regras, sob o risco de perder a terra.

Para alcançar o monopólio (domínio) dos modos de produção, o capitalismo realiza uma grande articulação daqueles modos pré-capitalistas, fazendo com que estes sejam integrados à ele e consequentemente dominados, e isto em ao menos três estágios, sendo: I afastar o produtor de suas ligações com a comunidade; II - separar o agricultor do artesão; III - separar o pequeno produtor de seus meios de produção. Assim, "espacialmente o desenvolvimento do capitalismo se caracteriza pela fixação de unidades de produção (capital fixo) em função de um cálculo de rentabilidade privada, tendo em conta a capacidade de apropriar-se de modo mercantil dos objetos de trabalho, e de escoamento de dos produtos no mercado" (LIPIETZ, 1988, p. 35).

Nesta linha, ao descrever o papel de domínio do capitalismo no campesinato parcelário francês, Lipietz (1988) aponta alguns aspectos que caracterizam ou facilitam esta dominação, sendo uma delas a ligação entre a pequena produção e o capital pelo que o autor chama de "duplo torniquete" que seria necessidade de aumento do volume dos negócios em decorrência da amortização das despesas.

Noutro ponto existe a dominação do processo de trabalho camponês pela indústria agroalimentar, que impõe a forma de trabalho, o "modo de emprego", como condições do contrato de compra e venda. Assim, os produtores teriam de seguir as regras capitalistas em toda sua linha de produção, inclusive nas relações de trabalho, sob pena de terem o contrato de venda de seus produtos para a indústria cancelado.

Ainda segundo Lipietz (1988) outros dois aspectos que caracterizaria a dominação dos meios de produção pelo capital seria a aplicação prática da teoria da mais-valia, ou seja, maximização do valor do produto em detrimento ao valor da hora de trabalho, além da Revista de Direito Urbanístico, Cidade e Alteridade | e-ISSN: 2525-989X | Salvador | v. 4 | n. 1 | p. 95 - 112 | 
influência dos juros provenientes de empréstimos para a aquisição de máquinas que somados aos lucros elevam o preço dos produtos, mas em contra partida, o investimento em máquinas faz aumentar a produção o que consequentemente poderá fazer com que os preços tenham que baixar (uma contradição do capitalismo), e desse modo o produtor passa a depender dos bancos para pagar suas dívidas.

É neste cenário, no qual o capital denota as regras de produção, decretando as formas de trabalho e a partir daí as delimitações dos espaços sociais, moldados aos interesses do capitalismo, que se pretende analisar como esta relação entre capital, espaço e trabalho interfere na delimitação do espaço urbano e no próprio direito à cidade a partir do mandamento constitucional da função social da cidade.

\subsection{Estado, capital, trabalho e o espaço urbano}

A partir do que foi abordado nos itens anteriores, é possível afirmar que o capital em si não teria uma materialização de riqueza específica ou um valor determinado, mas uma substância que seria a força do trabalho, sem a qual pereceria. Logo, quem dá o valor e a forma ao capital é o trabalho, sendo que este ao ser analisado por uma perspectiva capitalista, trata-se de um meio de produção que priva o trabalhador da propriedade do produto que ele mesmo produz.

Lembremos que o capital se forma como valor que se autonomiza de sua fonte produtora - o trabalho vivo - e a subordina a si, transformando-a em mercadoria que ele pode comprar - a força de trabalho. É como se o próprio capital se valorizasse, pelo fato de ter adquirido a fonte de criação do valor. E esta fonte também é a medida do valor, o "trabalho abstrato" que é determinado como "abstrato" pelo movimento social das trocas de mercadorias, presidido pelo capital em seu interesse de lucro. A autovalorização que define o capital é, com isso, também automensuração: ao dominar a força de trabalho, o capital pretende dominar a capacidade de se medir, de fixar a medida de valor que lhe corresponde em um certo momento e que ele quer e precisa superar enquanto valor que se valoriza. Medir-se, então, é algo crucial para o capital (GRESPAN, 2008, p. 9).

De início, parece algo muito simples, vez que a fórmula de dominação é aparentemente sem muitas complicações, e mesmo assim, ela se impõe e dita as regras de praticamente todos os segmentos sociais. Entretanto, o domínio capitalista se expande além da 
relação de trabalho, dos meios de produção e da propriedade privada, atingindo a política, a religião e até mesmo a produção do conhecimento.

Todavia, a alienação do trabalho e o controle dos modos produtores tornam-se a base de sustentação do capital, assim, o processo de trabalho encontra-se ligado a própria valorização do capitalismo, entretanto, o processo só se consolida se for acrescentado a esta fórmula, o instituto da propriedade privada, sendo esta relação a própria forma física e também o principal limite do capital. Sem ela o capital não existiria.

Assim, para validar seus domínios, o capital necessita de certa sustentação ou legitimação e ele irá buscar isto num sujeito específico, o Estado. Este sujeito passa a integrar a cadeia de relações do capital inserindo-se naquela anteriormente apontada. E quem é o Estado nesta relação capitalista? Qual o seu verdadeiro papel? Como ele atua junto ao modelo capitalista e quais ferramentas utiliza? Eis algumas das indagações que se pretende abordar a seguir.

Antes de tudo, cabe entender como o capital irá influenciar nas tomadas de decisões do próprio Estado, sendo que atuará como mecanismo de controle daqueles que são contrários, as formas de produção capitalista, e o fará principalmente na forma de meios políticos e legais de dissuasão (MÉSZÁROS, 2011). Neste mesmo sentido, destaca-se que

\begin{abstract}
No modo de produção capitalista, as relações de troca originam, portanto, noções específicas a respeito do "indivíduo", da "liberdade", da "igualdade", dos "direitos", da "justiça" etc. [...] Porém os conceitos desse tipo são mais do que meras ferramentas ideológicas. Elas se ligam ao Estado, incrustando-se formalmente no sistema legal burguês. O Estado capitalista deve, necessariamente, amparar e aplicar um sistema legal que abrange conceitos de propriedade, indivíduo, igualdade, liberdade, e direito, correspondente as relações sociais de troca sob o capitalismo (HARVEY, 2005, p. 83).
\end{abstract}

Para alguns teóricos, o Estado representaria uma vontade coletiva e esta deve se sobrepor à vontade individual através do ordenamento jurídico estatal. Entretanto, aponta Hans Kelsen (2000) que o ordenamento jurídico de um estado não representa necessariamente a vontade coletiva, pois se assim fosse, todos os indivíduos se submeteriam a lei sem a necessidade de imposição estatal, ou seja, sendo a ordem jurídica uma vontade comum, não haveria necessidade da existência do poder coercitivo do Estado para o cumprimento da lei. A criação de uma ideia de um interesse coletivo de Estado seria apenas uma forma de ocultar os conflitos de interesses sociais. 
Por esta ótica, pode-se sustentar a ideia de que o Estado assegura a proteção aos interesses das classes dominantes, em especial, o interesse do capital, sendo que a principal ferramenta que ele utiliza para isso é a legislação. Neste sentido, Marx já aponta esta parceria entre Estado e capital ao falar sobre as legislações europeias que proibia e punia inclusive com a morte aqueles que não estivessem trabalhando.

A criação do proletariado sem lar nem pão - despido pelos grandes senhores feudais e cultivadores, vítima de repetidas e violentas expropriações - era necessariamente mais rápida que sua absorção pela manufatura nascente. Por outro lado, estes homens, bruscamente arrancados de suas ocupações habituais, não se podiam adaptar prontamente à disciplina do novo sistema social [...] A legislação os tratou como criminosos voluntários supondo que dependia de seu livre arbítrio o continuar trabalhando [...] (MARX, 1981, p.57)

Desse modo, é possível sustentar que a participação do Estado em auxílio ao capital na formação do espaço urbano, objeto principal deste trabalho, se dará principalmente pela força lei. Ora, o capital irá defender a ideia de um espaço que seja favorável ao seu desenvolvimento, expansão e dominação, assim ele irá definir uma geografia urbana de modo a facilitar sua atuação, é neste ponto que o papel do Estado se encaixa, se entrelaçando na relação entre o capital, o trabalho, os meios de produção e a propriedade privada.

O Estado passa a ser parte decisiva nesta dinâmica social ministrada pelo capital, ao mesmo tempo em que não seria possível imaginar o funcionamento da máquina estatal moderna sem a participação capitalista, o que denota certa dependência do Estado para com o capital. Há, então, certa sintonia entre eles, como afirma Mészáros (2011), sendo que o capital passa a ser parte integrante da conjuntura política estatal numa verdadeira manifestação prática de reciprocidade dialética.

Este inter-relacionamento íntimo também se mantém quando visto pelo outro lado, pois o Estado moderno em si é totalmente inconcebível sem o capital como função sociometabólica. Isto dá às estruturas materiais reprodutivas do sistema do capital a condição necessária, não apenas para a constituição original, mas também para a sobrevivência continuada (e para as transformações históricas adequadas) do Estado moderno em todas as suas dimensões. Essas estruturas reprodutivas estendem sua influência sobre todas as coisas, desde os instrumentos rigorosamente repressivos/materiais e as instituições jurídicas do Estado, até as teorizações ideológicas e políticas mais mediadas de sua raison d'être e de sua proclamada legitimidade (Mészáros, 2011, p.125).

Assim, remontando a ideia de que os modos de produção, uma das fontes materiais do capital, e a produção do próprio espaço social, em especial do urbano, não poderia por ele 
ser desprezada. É neste ponto que se buscará discutir qual a relação entre o capital, o Estado e a produção do espaço urbano.

Para se entender de uma maneira mais prática a produção (formação) espacial urbana como produto capitalista, far-se-á uma análise ao caso da modernização urbanística pela qual passou a cidade de Paris, em meados do século XIX.

Como se sabe, o capitalismo necessita encontrar terrenos lucrativos de forma perpétua e o faz através das políticas de Estado que viabilizam a política do próprio capital. Em sistemática continua, o capitalismo dever gerar cada vez mais excedentes para assim reinvesti-los a uma taxa composta na produção de mais excedentes, numa relação entre o dinheiro, o produto e a população (consumidores). Assim o crescimento da urbanização passa a ser vital para a manutenção deste processo.

Neste sentido, a cidade de Paris sofreu, assim como outras cidades europeias, com uma grande crise do capital no ano de 1848, pois não conseguiu entregar de forma eficaz as exigências impostas pelo sistema capitalista da época. Neste cenário acontece uma frustrada revolução de trabalhadores desempregados e resulta na ascensão de Napoleão Bonaparte que se proclama imperador da França em 1852. A partir daí a base da reorganização da política econômica francesa será a infraestrutura, sendo que para isso, o novo Imperador nomeará Georges-Eugène Haussmann como o encarregado das obras públicas, que por vez acarretará na reconfiguração urbana da capital francesa (HARVEY, 2015).

A nova Paris fora concebida e executada para escoar o excedente do capital, sendo que suas obras de urbanização foram bancadas por empréstimos junto a instituições financeiras num grande sistema de financiamento da infraestrutura urbana.

O sistema funcionou bem por uns quinze anos e envolveu não apenas a transformação da infraestrutura urbana, mas também a construção de uma nova maneira de vida pessoal e urbana. Paris se tornou "a cidade das luzes", o grande centro de consumo, turismo e prazer, os cafés, as lojas de departamento, a indústria da moda e as grandes exposições mudaram o modo de vida para que pudesse absorver vastos excedentes através do consumismo. Mas, em seguida, o sistema financeiro e a estrutura de crédito, extensivos e especulativos, quebraram em 1868. Haussmann foi demitido (HARVEY, 2012, p.76).

Por esta ótica, não se pode afastar o inter-relacionamento entre o capital financeiro, o interesse ou especulação imobiliária e o Estado, como parte de arrojado processo de escoamento do capital excedente através de altos valores de aluguéis, empréstimos e impostos. 
Entretanto, este processo de criação do espaço urbano, seguindo os preceitos do capital, não foi algo exclusivo da Paris de meados do século XIX, pelo contrário, este mesmo processo é sentido na atualidade a nível global. Diante de certa falta de coisas para produzir, o capital encontrou na urbanização uma nova forma de mercado que possibilitaria a acumulação de lucros através da concentração crescente da urbanização como um meio de acumulação de capital.

A urbanização passa a ser vista como uma caminhada a ser seguida na busca por uma acumulação perpetua de capital, mas não seria qualquer tipo de urbanização, esta teria que ser de proporções globais. O grande diferencial da urbanização global é que além do consumo planetário de capital, ele acaba por criar novos mercados e este modelo é utilizado como meio de estabilização do próprio capitalismo (HARVEY, 2015).

A expansão urbana passa a ser vista como produto capitalista de alta rentabilidade, assim, a cidade acaba por ser tratada como uma verdadeira zona de exploração capitalista onde o que mais interessa é o lucro advindo da especulação imobiliária e de outras facilidades ofertadas ao capitalismo, mesmo nas obras públicas a real intenção é faturar e não alcançar o bem-estar dos cidadãos.

\subsection{Da função social da cidade em contraponto ao modelo capitalista de construção do espaço urbano}

Com o fenômeno da grande expansão dos centros urbanos, decorrente de diversos fatores, especialmente após o grande processo de industrialização, somado a outros elementos gerados pelo capital como abordado anteriormente, e que ocasionaram no decorrer da história um verdadeiro êxodo do campo para a cidade, se faz necessário pensar em um planejamento e uma estruturação urbana que seja capaz de atender as demandas sociais, desde as mais simples até as mais complexas.

Considerando o espaço urbano como um meio ambiente artificial fruto da atividade humana, ao mesmo tempo que a população mundial tem aumentado de forma geométrica nas últimas décadas devendo chegar, segundo a ONU, ao patamar de 11 bilhões de pessoas até o ano de 2100, e que a maioria dessa população ocupará os centros urbanos, a discussão sobre a temática do desenvolvimento social urbano é vital para se compreender melhor os impactos 
sociais, econômicos e ambientais causados pelo ação humana ao meio ambiente artificial urbano.

Destarte, não é mais plausível imaginar que a organização e o planejamento urbano possam ser feitos de qualquer modo, ou que possa ser deixado à mera discricionariedade da administração pública. Neste sentido, a Constituição Federal de 1988 determina que a cidade seja pensada de maneira a desenvolver suas funções sociais em prol de garantir o bem-estar de seus habitantes.

Pelo fato de ser um ambiente coletivo, a cidade deve ser pensada como um direito de todos, com vistas a alcançar o desenvolvimento de suas funções sociais. Assim, o art. 182 da Constituição Federal afirma que para alcançar suas funções sociais, o município deve traçar uma política de desenvolvimento urbano, o que nos leva a considerar que a função social da cidade é precipuamente o desenvolvimento.

Neste sentido, o poder público municipal deve buscar atingir o desenvolvimento urbano como forma de satisfazer as funções sociais da cidade, sendo o instrumento básico para a política de desenvolvimento das cidades com mais de vinte mil habitantes é o Plano Diretor, aprovado pela Câmara Municipal (art. 182, § $1^{\circ}$, da Constituição Federal).

Os objetivos da política de desenvolvimento urbano trazida pela Constituição Federal de 1988 seriam: I - o pleno desenvolvimento das funções sociais da cidade que consiste na efetivação de direitos fundamentais como à vida, à segurança, à igualdade, à propriedade, à liberdade, à educação, à saúde, ao lazer, ao trabalho, à previdência social, à maternidade, à infância, à assistência aos desamparados, dentre outros; II - a garantia do bem-estar de seus habitantes, proporcionando além da execução e efetivação das funções sociais da cidade uma sensação de bem-estar, traduzida pelo alcance dos valores exigidos constitucionalmente (FIORILLO, 2013).

Não é salutar permitir a prática de investimentos mal planejados do ponto de vista ambiental e urbanísticos em nome de um possível crescimento econômico. Pelo contrário, é necessário, antes de tudo, pensar num “[...] novo padrão civilizatório para a humanidade, que pondera a justiça ambiental com a sustentabilidade social” (FEITOSA, 2013, p.48).

Desse modo, há que se destacar que o desenvolvimento exigido pela Constitucional transcende as barreiras do modelo tradicional do mero crescimento econômico. Para Juarez Freitas (2012), este desenvolvimento trata-se de um dos valores constitucionais supremos e 


\title{
O ESPAÇO URBANO E O CAPITAL: UMA ANÁLISE A PARTIR DO PRECEITO \\ CONSTITUCIONAL DA FUNÇÃO SOCIAL DA CIDADE
}

um dos fundamentos da República Brasileira que deve ser conjugado, interna e externamente, à noção de sustentabilidade.

O ponto é que, quando a Constituição fala em desenvolvimento como valor supremo e como objetivo fundamental, quer necessariamente adjetivá-lo como sustentável, intertemporal e durável. Melhor do que isso: pretende que a sustentabilidade fixe os pressupostos (sociais, econômicos, ambientais, jurídico-políticos e éticos) de conformação do desenvolvimento constitucionalmente aceitável (FREITAS, 2012, p.110).

De fato, é imprescindível pensar o meio ambiente de forma sustentável, e esta vertente não difere ao pensarmos especificamente no meio ambiente artificial urbano. Nesta linha, o legislador constituinte afirma que a cidade atingirá sua função social ao cumprir as exigências trazidas no plano diretor (art. 182, § $2^{\circ}$ da Constituição Federal), logo, se supõe que o planejamento urbano é passo fundamental para se alcançar uma cidade desenvolvida e sustentável.

Até o advento da Constituição Federal de 1988, pode-se dizer que o planejamento urbano dependia da mera vontade do administrador público, ou seja, não havia uma vinculação ou obrigatoriedade jurídica que impusesse a criação ou utilização de um instrumento de planejamento.

Com a promulgação da Carta Magna em 1988, ocorreu o que José Afonso da Silva (2010) denomina de institucionalização do processo de planejamento urbano.

\begin{abstract}
Atualmente a questão tomou outros rumos e sofreu radical transformação, porque o processo de planejamento passou a ser um mecanismo jurídico por meio do qual o administrador devera executar sua atividade governamental na busca da realização das mudanças necessárias a consecução do desenvolvimento econômico-social (SILVA, 2010, p. 88).
\end{abstract}

O processo de planejamento do meio ambiente artificial urbano encontra respaldo constitucional e se materializa nos planos diretores municipais, porém, segundo aponta o autor supracitado, existe certo embate doutrinário em relação a natureza jurídica dos planos. Neste sentido, o mesmo esclarece que:

Em sentido formal, portanto, os planos urbanísticos no Brasil tem natureza de lei, e também o tem no sentido material, pois, como ja vimos, são conformadores, transformadores e inovadores da situação existente, integrando o ordenamento jurídico que modificam, embora neles se encontrem também regras concretas de natureza administrativa, especialmente quando sejam de eficácia e aplicabilidade imediatas e executivas (SILVA, 2010, p. 96). 
Além da exigência constitucional, a elaboração e efetivação do plano diretor passa a ter uma normatização infraconstitucional com o advento da Lei $\mathrm{n}^{\circ} 10.257 / 01$, intitulada de "Estatuto da Cidade", que amplia o leque de abrangência do plano diretor municipal, fazendo com que o mesmo atinja todo o território da cidade, o que inclui também a zona rural.

O Estatuto da Cidade inova ao criar a expressão "ordem urbanística” que, nas palavras de Paulo Machado (2011, p. 412), diz respeito ao "conjunto de normas de ordem pública e de interesse social que regulam o uso da propriedade urbana em prol do bem coletivo, da segurança, do equilíbrio ambiental e do bem-estar dos cidadãos”.

Nestes termos, é possível considerar que o planejamento urbano deve ser pautado em uma relação harmoniosa entre o ser humano e o meio ambiente artificial, levando-se em consideração as funções sociais da cidade e os preceitos do desenvolvimento sustentável como pressupostos para a manutenção da ordem ambiental e urbanística e efetivação do bemestar de todos, diferentemente do que ocorre no modelo capitalista onde o social é posto de lado em prol de interesses econômicos transformando a cidade num grande meio de produção e escoamento dos interesses capitalistas.

\section{3 - CONSIDERAÇÕES FINAIS}

Assim como o capital, perpetuamente busca desenvolver meios de gerar demandas promotoras de lucratividade, ou seja, de concentração de capital a partir da apropriação do produto do trabalho de outrem, o que acontece com tantas cidades, é o desenvolvimento de políticas de investimentos imobiliário através de vários empreendimentos, seja a criação de loteamentos, de condomínios fechados populares e de elite, onde vastas extensões de terras são desmembradas em nome da especulação imobiliária.

O capital se reinventa nas crises, é assim que ele sobrevive. Desse modo, a especulação imobiliária nada mais é que um puro reflexo da interferência do capital no desenvolvimento urbano, que não busca o desenvolvimento sustentável, mas apenas uma nova injeção de capital nas economias locais. Assim, a expansão urbana é pensada apenas como mais um produto capitalista e não como uma necessidade social.

Portanto, através da remodelação do espaço, o mercado capitalista da cidade ganha fôlego lucrativo imprimindo novos modelos de habitação, com custos de construção muito 
mais elevados que produzem, um sentido de novos hábitos e costumes, novos gostos e parâmetros de estrutura arquitetônica, impulsionando aqueles habitantes que contam com dinheiro em reserva a retirarem estes de suas "poupanças", para aplicarem num "investimento rentável", e do outro lado, obrigando os sujeitos a trabalharem mais ou a explorarem mais o trabalho de outrem para angariar mais capital e assim manter o seu ciclo de domínio.

Nestes termos, é possível considerar que o planejamento urbano não condiz com princípio constitucional da função social da cidade, pois da forma como vem sendo historicamente efetuado, serve apenas como ferramenta de lucratividade para o capitalismo.

Contudo, o que se propõe é um desenvolvimento urbano pautado não nos interesses do domínio econômico, mas numa relação harmoniosa entre o ser humano e o meio ambiente urbano, levando-se em consideração além do princípio da função social da cidade, os preceitos voltados ao desenvolvimento sustentável como pressupostos para a manutenção da ordem ambiental e urbanística e buscando efetivação do bem-estar de todos habitantes que nela residem.

\section{REFERÊNCIAS BIBLIOGRÁFICAS}

BRASIL. Constituição da República Federativa do Brasil: texto constitucional promulgado em 5 de outubro de 1988, consolidado até a Emenda Constitucional n 95/2016. Brasília: Senado Federal, 2016.

FEITOSA, Maria Luiza Alencar Mayer; FRANCO, Fernanda Cristina Oliveira; PETERKE, Sven; VENTURA, Victor Alencar Mayer Feitosa. Direitos Humanos de Solidariedade: avanços e impasses. Curitiba: Aprris, 2013.

FIORILlO, Celso Antonio Pacheco. Curso de direito ambiental brasileiro. 14. ed. rev., ampl. e atual. São Paulo: Saraiva, 2013.

FREITAS, Juarez. Sustentabilidade: direito ao futuro. 2. ed. Belo Horizonte: Fórum, 2012.

GRESPAN, Jorge Luis da Silva. A desmedida do capital. In: Cadernos de Ética e Filosofia Política. SP: FFLCH-USP, nº 13, $2^{\circ}$ semestre, 2008, p. 7-16.

HARVEY, David. A produção capitalista do espaço. São Paulo: Annablume, 2005. Direito à cidade. In: Lutas Sociais, São Paulo, n.29, p.73-89, jul./dez. 2012. 
Paris capital da modernidade. São Paulo: Boitempo, 2015.

HUBERMAN, Leo. História da riqueza do homem. 17. ed. Rio de Janeiro: Zahar Editores, 1981.

KELSEN, Hans. Teoria geral do direito e do Estado. 3.ed. São Paulo: Martins Fontes, 2000.

LEFEBVRE, Henri. A produção do espaço. Trad. Doralice Barros Pereira e Sérgio Martins (do original: La production de l'espace. 4e éd. Paris: Éditions Anthropos, 2000). Primeira versão: início - fev.2006

O direito à cidade. São Paulo: Centauro, 2001.

LIPIETZ, Alain. O capital e seu espaço. São Paulo: Nobel, 1977.

MACHADO, Paulo Affonso Leme. Direito ambiental brasileiro. 19. ed. rev., atual. e ampl.

São Paulo: Malheiros, 2011.

MARX, Karl. A ideologia alemã: crítica da mais recente filosofia alemã em seus representantes. São Paulo: Boitempo, 2007.

. A origem do capitalismo: a acumulação primitiva. 4. ed. São Paulo: Global editora, 1981.

MÉSZÁROS, István. Para além do capital: rumo a uma teoria da transição. São Paulo: Boitempo, 2011.

SANTOS, Milton. A Natureza do Espaço: espaço e tempo, razão e emoção. São Paulo: Editora da Universidade de São Paulo, 2002.

Espaço e método. 4. ed. São Paulo: Nobel, 1997.

. Metamorfoses do espaço habitado. São Paulo: Hucitec, $4^{\text {a }}$ ed, 1996.

SILVA, José Afonso da. Direito Urbanístico Brasileiro. 6. ed. rev. e atual. São Paulo: Malheiros, 2010. 